\title{
The Influence of functional training on biomotor skills in girl tennis players aged 10-12
}

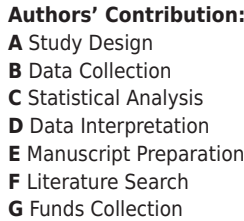

\author{
Oktay Zırhlı ${ }^{1 \text { ABCEF }}$, Nevzat Demirci² ACDEF \\ ${ }^{1}$ Department of Physical Education and Sports, Mersin University, Mersin, Turkey \\ ${ }^{2}$ Faculty of Sports Sciences, Mersin University, Mersin, Turkey
}

\section{abstract}

Background: The purpose of this study is to examine whether functional training has an impact on biomotor skills of 10-12-year-old girls.

Material and methods:

The study involved 20 girls (10 controls and 10 subjects) - who had been playing tennis for at least 2 years. A routine tennis training program was applied to the control group of tennis players participating in the study: 4 days a week, 90 minutes a day for 8 weeks. A $2+2$ training program ( 2 days routine and 2 days functional training) was applied to the experimental group of tennis players for 8 weeks, 4 days a week, 90 minutes a day. At the end of the training program, biomotor tests were conducted.

Results: There was not any significant differences when the pre-test and post-test values of the control group of tennis players who performed traditional tennis training were compared with their biomotor skills and Wingate anaerobic power $(p>.05)$. When the pre-test and post-test values of the experimental group of tennis players with 8-week functional tennis training were compared with their biomotor skills and Wingate anaerobic power, a significant difference was found in all variables $(p<0.01)$.

Conclusions: The obtained data shows that the "functional training" programs implemented together with "routine tennis training" can positively improve the biomotor characteristics of 10-12 year-old girl tennis players.

Key words: functional training, tennis, biomotor skills, Wingate test.

\section{article details}

Article statistics: Word count: 3,937; Tables: 7; Figures: 2; References: 35

Received: January 2020; Accepted: October 2020; Published: December 2020

Full-text PDF: http://www.balticsportscience.com

Copyright ๑ Gdansk University of Physical Education and Sport, Poland

Indexation: Celdes, Clarivate Analytics Emerging Sources Citation Index (ESCI), CNKI Scholar (China National Knowledge Infrastructure), CNPIEC, De Gruyter - IBR (International Bibliography of Reviews of Scholarly Literature in the Humanities and Social Sciences), De Gruyter - IBZ (International Bibliography of Periodical Literature in the Humanities and Social Sciences), DOAJ, EBSCO - Central \& Eastern European Academic Source, EBSCO - SPORTDiscus, EBSCO Discovery Service, Google Scholar, Index Copernicus, J-Gate, Naviga (Softweco, Primo Central (ExLibris), ProQuest - Family Health, ProQuest - Health \& Medical Complete, ProQuest - Illustrata: Health Sciences, ProQuest - Nursing \& Allied Health Source, Summon (Serials Solutions/ProQuest, TDOne (TDNet), Ulrich's Periodicals Directory/ulrichsweb, WorldCat (OCLC)

Funding: This research received no specific grant from any funding agency in the public, commercial, or not-for-profit sectors.

Conflict of interests: Corresponding author:

Open Access License:
Authors have declared that no competing interest exists.

Oktay Zırhli; Mersin University, Department of Physical Education and Sports, Mersin/Turkey;

e-mail: oktayzirhli@gmail.com; https://orcid.org/0000-0002-6602-7500X

This is an open access article distributed under the terms of the Creative Commons Attribution-Non-Commercial-NoDerivatives 4.0 International (https://creativecommons.org/licenses/by-nc-nd/4.0/), which permits use, distribution and reproduction in any medium, provided the original work is properly cited, the use is non-commercial and is otherwise in compliance with the license. 


\section{INTRODUCTION}

Functional training contributes to different systems of the body with functional exercises in different parts of the body (covering the whole body, developing universal motor skills, applied in multiple motion planes) through intensive, short and constantly changing sessions [1, 2, 3]. In the literature, practices created as a form of functional training have different resting rates with similar training content (gymnastics, weightlifting, aerobic exercises, etc.) [4, 5]. Along with functional training capacity, muscle endurance is associated with strength and a positive increase in body composition with the potential to increase strength [2, 6, 7 ]. While endurance largely depends on the aerobic capacity of the athlete, it is less dependent on anaerobic capacity [8]. Functional training, while simultaneously increasing athletes' muscular endurance, hypertrophy, power and strength, also creates an excellent impact to improve aerobic power and anaerobic capacity $[9,10]$.

Success in tennis depends on numerous factors such as physical condition, technical skill and tactical strategy [11]. The physiological requirements of tennis are quite complicated because it covers all of the strength, short distance runs and endurance exercises in the game. With this aspect, controversy among many sports scientists, tennis coaches and players continues as regards the implementation of training programs. In this way, the question of which aerobic or anaerobic energy systems are dominant in tennis is addressed [12]. The question is examined in five sections according to the contextual structure of the basic motor qualities. The first three are basic and the other two are complementary. These qualities include strength, speed, flexibility, mobility, coordination. The basic motor qualities of an individual consist of the elements that determine the person's body strength and ability and the degree of complex motor power. These qualities are the basis and the primary condition for every motor sports movement performed during the functional training process. The development of basic motor features in all sports is an indispensable part of the applied training [13]. Kinematics and the associated factors of performance are essential for trainers to help the player to develop his/her skills and to improve performance.

While specific training is planned to develop a specific area or a specific feature, combined training aims to co-develop the basic biomotor qualities. Especially in combined trainings, it is a prerequisite to work in strength, speed, endurance, technical and tactical integrity. With functional training, both to improve strength characteristics and to train in a unity with flexibility, speed, endurance, mobility and coordination has been aimed. The idea was that the development of all these biomotor qualities in sports development could be done in single training $[14,15]$. It is designed to increase the quality and sports performance of daily life activities. It targets the neuromuscular system; namely, it trains not only muscles, but also movements. It involves functional training, dynamic and static balance, and challenges to improve coordination and proprioception, using a staged and individualized program in a multi-joint and multi-plane exercise program [16]. In this study, it is presumed that functional training to be performed according to the branch-specific age period will increase the functional capacity of the athletes and further increase their sports performance in the future [17].

It is suggested that functional training positively influences sports performance, especially in singles tennis. As the training programs are renewed with the developed functional training programs and in the light of science, it is observed that their success in tennis sports also increases [18]. In order to train internationally successful athletes, it is critical to implement appropriate training programs. Functional training practices will improve the basic movement skills of tennis players, while at the same time, it will enable children to easily perform sports-specific movement skills at the age of expertise. With this study, it is important that athletes contribute to improving their biomotor skills, and positive 
changes are reflected in tennis performance. The aim of this study is to investigate whether functional training has an impact on biomotor skills of 10-12-year-old girls.

\section{MATERIAL AND METHOD}

\section{Participants}

Mersin University Non-Interventional Ethics Committee's approval was received for the study. Participants were informed about the issues, potential risks and benefits before participating in the study, and written informed consent was obtained for their participation in accordance with the Helsinki Declaration's policies and procedures. Written consent was also approved by the parents of all minors participating in the study. Volunteer participants were selected from tennis clubs active in Mersin. Girl athletes between 10-12 years old who had been playing tennis for at least 2 years were preferred. Measurements were initiated with 26 athletes (age: $11.20 \pm 0.834$, height: $148.50 \pm 7.57$, body weight: 41.29 \pm 7.23 and body fat percentage: $22.21 \pm 4.50$ ), and 6 persons who were not suitable to the criteria and were not included in the study (Fig. 1).

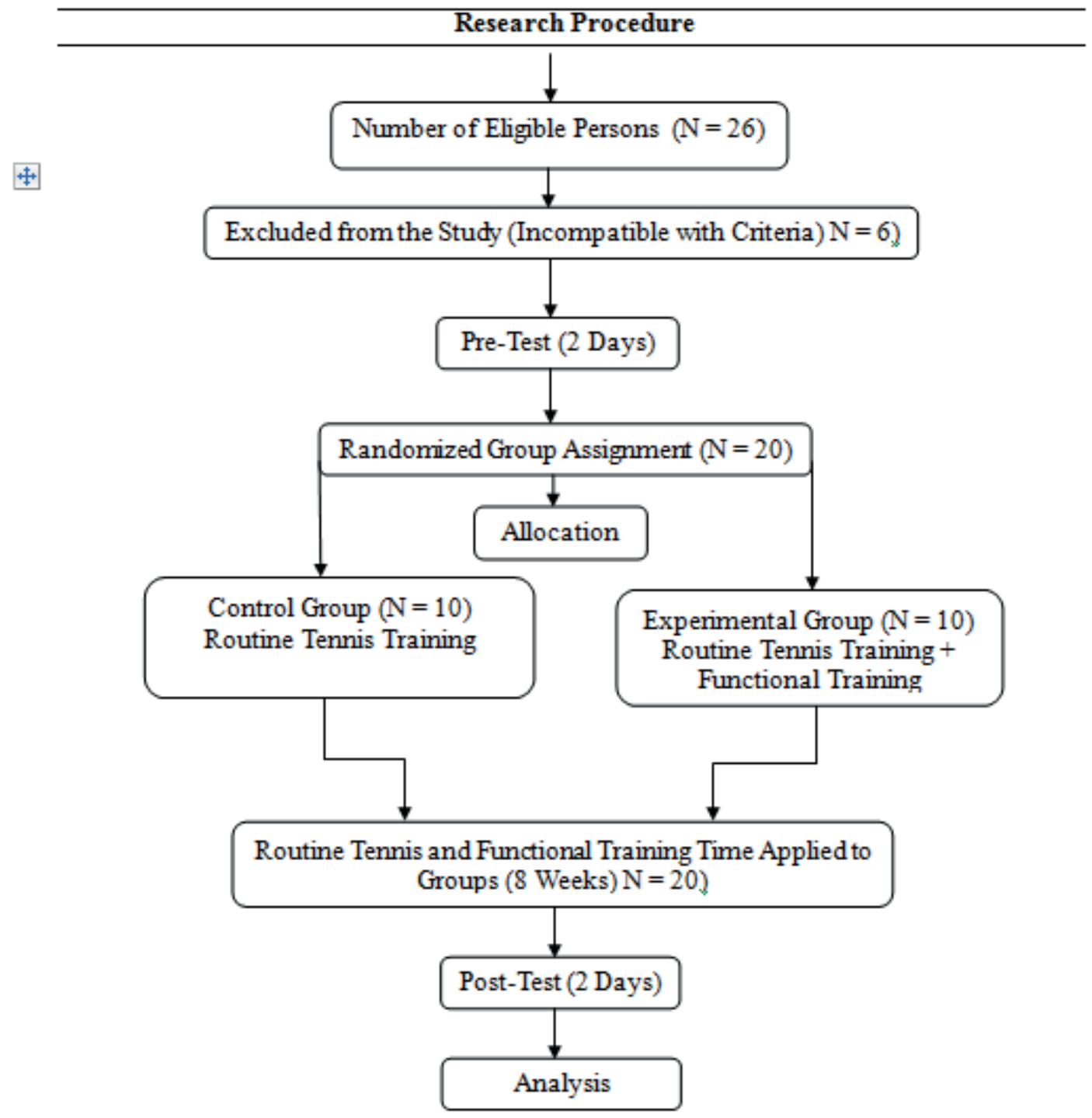

Fig. 1. Flow diagram representing study design 
The study was continued with 10 persons in CG and 10 persons in EG. A presentation including the details of the training program was made by giving information about the aims of the study, research design, training program, measurement procedure, participant responsibility to the participants and their parents. Participants were allowed to participate in the first measurements and continue training regularly. The measurement procedure was introduced in detail to each subject, and a summarized information package describing their responsibilities to participate in the training program was delivered. Participants from both groups were provided with regular diet and exercise routines.

\section{RESEARCH MODEL}

In the study, an experimental model with a control group including pre-test-post-test measurements was used. Participants were divided into the control group (CG) and the experimental group (EG) by randomized appointment. The routine tennis training program was applied to the control group of tennis players participating in the study, 90 minutes a day, 4 days a week for 8 weeks. The $2+2$ (2-day routine tennis training and 2-day functional training) program was applied to the experimental group of tennis players for 4 days a week, 90 minutes a day, for 8 weeks.

\section{TESTS APPLIED BEFORE THE TRAINING PROGRAM}

Bioelectrical impedance analysis measurements

Height and weight measurements were made to determine the individuals' anthropometric characteristics, and body fat percentage were determined with the method of bioelectric impedance analysis (Tanita 418-MA Japan). Bioelectric impedance analysis was performed by the same person on the first measurement day. The body weight (BW) was calculated with the subjects wearing standard sportswear (shorts, tops) without shoes, with $( \pm 0.1)$ error margin on the weighbridge (T Tanita 418-MA JApan). Their heights were calculated with heads on the frankfort plane, following deep inspiration and with the measurement of the distance between the vertex of the head and the foot with a use of a stadiometer (Holtain Ltd. U.K.) with an error margin of $( \pm 1 \mathrm{~mm})$. Anthropometric measurements of individuals were taken before both tests on different days.

\section{Biomotor performance measurements}

The variables of the study were composed of biomotor performance components, including the 10-m Speed Test, Vertical Leap Test, Sit Down Test, Grip Force Test, Agility Test (T Test) and Anaerobic Power. The tests of both groups were carried out as a pre-test at the beginning and post-test at the end of the study. Participants were taken to the test after warm-up of 5 -minute light pace running and then 5 minutes of stretching exercises for each test.

\section{0-m Speed Test}

The participants' speed performance was measured using a stopwatch in the area marked with a distance of 10 meters. At the starting point, the athlete took a standing position with one line in the front and the other in a linear standing static position. No swinging was allowed in any way. Between each run, athletes were given complete rest and asked to do 3 maximum repetitions. The best time was recorded [19].

\section{Vertical Leap Test}

Vertical Leap is measured as the vertical jump value of the individual by measuring the difference between the most extreme point that a person can reach by stretching her arm against the wall and the highest point she can touch by jumping. The measurement was repeated three times and the highest value was recorded for analysis.

\section{Sit-and-Reach Test}

Athletes' flexibility was evaluated by the sit-and-reach test. Athletes were in a long sitting position with both knees in full extension, ankles at 90 degrees and their feet bare. 
Athletes were asked to lean forward as long as they can with their hands in front of their bodies without bending their knees and wait 2 seconds at the last point they can reach. The difference between baseline and the reach was measured in centimetres $(\mathrm{cm})$. The measuring person stood next to the participants and prevented their knees from bending. The measurement was repeated three times and the highest value was recorded for analysis.

\section{Hand Grip Strength Test}

The right and left hand-grip forces of the athletes included in the study were measured before and after the training with the help of a hand dynamometer (CAMRY brand, EH 101 model digital LCD Dynamometer, resistant to $90 \mathrm{~kg} / 198 \mathrm{lb}$ resistance). Handgrip force measurements were performed with the arms hanging down and at an angle of 180 degrees without bending the elbow. Measurements were performed in the same way for both arms. Force measurements were repeated three times, the arm without measurement did not receive support from anywhere. The measurement of each athlete was performed by calibrating the dynamometer and adjusting the dynamometer according to the hand and finger characteristics of the athlete.

\section{Agility Test (T Test)}

Agility performance was measured using a stopwatch (OnnPnnQ Brand, PC2810 model) on the track prepared for athletes. The "T" test is an agility test that requires running forward, sideways and backwards for athletes. Equipment needed for this test includes meters, sign cones, stopwatch and timing lines. When the athlete felt ready while waiting for both feet to be behind the starting line (point A), she exited and ran from the "A" cone to the "B" cone with a straight run and touched the cone with her right hand. Then she ran left to the "C" cone with a side run and touched the " $\mathrm{C}$ " cone with her left hand, then she ran to the right to the " $\mathrm{D}$ " cone with her right hand. Then she came to the " $\mathrm{B}$ " cone, came with a side run and touched it with her left hand, then returned to the "A" cone with a back run. As soon as she reached the "A" cone, the stopwatch was stopped and the duration was recorded. In this study, the participant performed 3 repetitions with full rest and the time obtained at the end of the test was recorded in seconds.

\section{Wingate Anaerobic Power Test}

Anaerobic powers of the experimental and control group athletes were evaluated with the Wingate test (WAnT), which can be applied on a bicycle ergometer (Ergoline Ergoselect $100 / 200$ brand). The Wingate test is a supramaximal test lasting 30 seconds. When the subject reached the maximal pedal speed without load, the determined load per body weight $(75 \mathrm{~g} / \mathrm{kg}$ ) was applied as resistance. The number of pedals is recorded for every 5 seconds.

\section{Procedure}

Applied training procedure

Both training programs in the research consisted of three phases:

1. a warm-up phase (running and dynamic stretching exercise) $15 \mathrm{~min}$.

2. the main exercises (loading) phase $60 \mathrm{~min}$.

3. active cooling phase (running and static stretching exercise) $15 \mathrm{~min}$.

\section{Routine tennis training program}

The routine tennis training program, which both groups practiced, was initiated with a 15-minute warm-up phase and completed with a 15-minute cool-down phase after the 60-minute main phase, where tennis-specific stroke techniques were applied. In this training, the athletes were asked to play with an estimated power intensity of $75 \%$. The participation of athletes in the training program for 8 weeks was ensured with their 
coaches' support. Throughout the training, the durations and resting frequency in the program was adhered to in the way specified to the athletes (Table 1).

Table 1. 8-week routine tennis training program (a sample week)

Day 1:

Manual low-ball feed, 100 forehand $(\mathrm{Fh})$ strokes on the incoming ball.

Manual low-ball feed, 100 backhand (Bh) strokes on the incoming ball.

Flat feeding with racket, spinning incoming ball $100 \mathrm{Fh}$. strike.

Flat feeding with racket, spinning incoming ball $100 \mathrm{Bh}$. strike.

Baseline also $100 \mathrm{~cm}$ long hand feed from the front of the obstacle, high spin on the incoming ball, 100 Fh. strike.

Baseline $100 \mathrm{~cm}$ long hand feed from the obstacle, high spin on the incoming ball, 100

Bh. strike.

Midi field-to-field "drive vole" training $100 \mathrm{Fh}$. strike.

Midi field-to-field "drive vole" training $100 \mathrm{Bh}$. strike.

Feeding the "slice" from the opposite field with the racket, spinning the incoming ball 100 Fh. strike.

Feeding the "slice" from the opposite field with the racket, spinning the incoming ball 100 Bh. strike.

Day 2:

Cross forehand rally in the height-increased net,

Cross backhand rally in height-increased net,

Parallel forehand rally in the height-increased net,

Parallel backhand rally in the height-increased net,

Mixed rally in an increased height net.

Day 3:

Low ball feed in front of the net, spinning the incoming ball, 100 forehand strokes.

Low ball feeding in front of the net, spinning the incoming ball, 100 backhand strokes.

100 forehand strokes "drive volley" on the low ball in the mini field.

100 backhand strokes "drive volley" on the low ball in the mini field.

\section{Day 4:}

The service boxes of the field were closed, and deep ball exercises were applied to the baseline with mixed techniques.

While this study was carried out for 8 weeks, different direction and intensity hitting techniques were used for different angles of the court, and enrichment of the study was considered. The direction and intensity of ball feeding techniques were changed from time to time. By hand or racket flings, bouncing and feeding with mixed techniques, the athletes were asked to respond to the incoming balls with mixed, circular strokes. With similar studies, while athletes were sometimes directed to a target, from time to time, short or long balls of different heights were thrown. On the last training day of the fourth and eighth weeks of the program, some analysis and evaluations were made by monitoring the athletes with in-point matches.

\section{Functional training program}

2-day functional training program was prepared in addition to the 2-day routine tennis training program (Table 2), and for this training program the maximum heart rate was $75 \%$ and above. It was delivered by the researcher for 8 weeks according to the athletes' performance. The prepared training program was chosen from movements that complement 
the kinetic chain and improve the athletes' biomotor skills. These movements are made up of exercises for muscles and muscle groups used in kicking techniques such as pushing, pulling, rotation, squatting, getting up and jumping, and forming the kinetic chain of this technique. These athletes also continued their routine tennis training programs.

Table 2. 8-Week functional training program (a sample week)

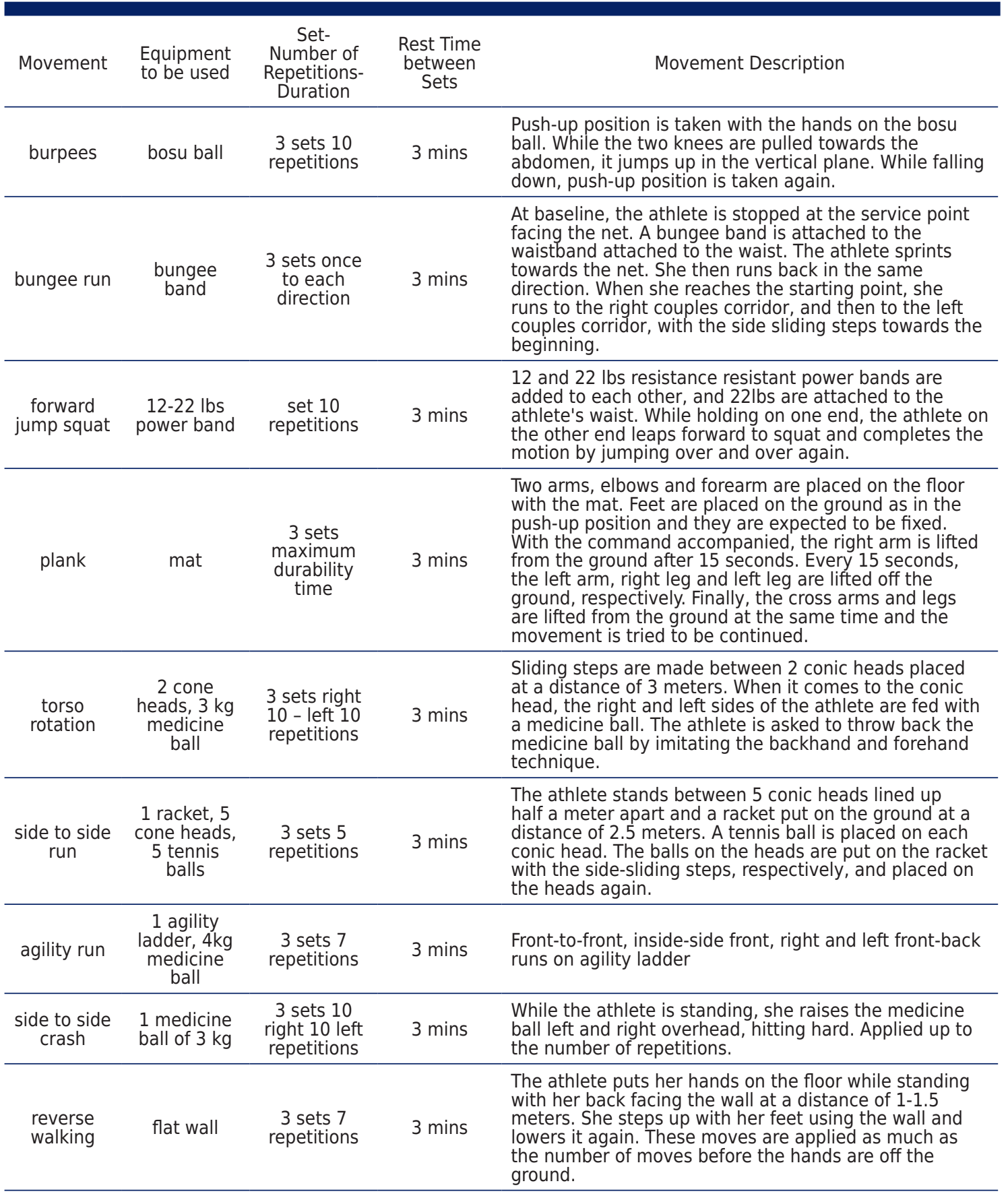

\section{STATISTICAL ANALYSIS}

Mean and standard deviation values were used as descriptive statistics. The research data were analysed separately for each sub-problem. Two-way analysis of variance was applied for mixed measurements to determine whether there is a difference between pre-test-posttest applications in the experimental and control groups. However, in order to perform this analysis, the basic assumptions of the analysis (normality, equality of covariance matrices, 
equality of error variances and equality of error covariance matrices) had to be tested [20]. In testing basic assumptions of variance analysis for mixed measurements, Shapiro Wilk normality test, Box's M covariance matrix test, Levene's error variance test and Mauchly's sphericity error covariance matrices were performed. Due to normal distribution of the groups, paired samples T-Test was used in group comparisons. Statistical results were evaluated at $95 \%$ confidence range and $\mathrm{p}<0.05$ significance levels.

\section{RESULTS}

Table 3 presents demographic and anthropometric parameters of all participants in the control and experiment groups. Because there is no significant difference between anthropometric and demographic parameters, such as age, height, body weight and body fat percentage between groups, it can be stated that the difference in the parameters related to biomotor skills ( $10 \mathrm{~m}$ speed run, vertical jump, flexibility, hand grip force, $\mathrm{t}$ test) and Wingate measurements between groups is not due to anthropometric and demographic features.

Table 3. Demographic and anthropometric parameters of all participants in the study

\begin{tabular}{ccccc} 
Variable & N & Min. & Max. & Average \pm S.S. \\
\hline Age (year) & 20 & 10 & 12 & $11.20 \pm 0.834$ \\
Height $(\mathrm{cm})$ & 20 & 137.00 & 163.00 & $148.50 \pm 7.57$ \\
BW $(\mathrm{kg})$ & 20 & 29.20 & 57.60 & $41.29 \pm 7.23$ \\
BFP (\%) & 20 & 13.60 & 33.10 & $22.21 \pm 4.50$
\end{tabular}

BW: body weight, BFP: body fat percentage

When comparing the pre-test and post-test values related to the biomotor skills of the control group of tennis players with traditional tennis training, it was determined that there was no significant difference ( $p>.05)$ (Table 4). When the pre-test and post-test values related to the biomotor skills of the experimental group of tennis players with 8-week functional tennis training were compared, it was found that there was a significant difference in all variables $(p<0.01)$ (Table 5).

Table 4. Comparison of the pre-test and post-test values of the 8-week routine tennis training in the control group

\begin{tabular}{|c|c|c|c|c|c|c|}
\hline Group & Variables & Test & $\mathrm{N}$ & $\overline{\mathrm{x}}$ & sS & $P$ \\
\hline \multirow{12}{*}{ Control } & 10-m. Speed Run (s) & Pre-test & 10 & 2.46 & 0.24 & \multirow[t]{2}{*}{.194} \\
\hline & 10-m Speed Run (s) & Post-test & 10 & 2.49 & 0.23 & \\
\hline & Vertical Leap (kg.m/sn) & Pre-test & 10 & 18.50 & 7.99 & \multirow[t]{2}{*}{.751} \\
\hline & Vertical Leap (kg.m/sn) & Post-test & 10 & 18.70 & 8.01 & \\
\hline & Flexibility (cm) & Pre-test & 10 & 6.50 & 5.38 & \multirow[t]{2}{*}{.226} \\
\hline & Flexibility (cm) & Post-test & 10 & 7.20 & 4.59 & \\
\hline & Hand Gripping Force (kg)-right & Pre-test & 10 & 20.94 & 4.18 & \multirow[t]{2}{*}{.401} \\
\hline & Hand Gripping Force (kg)-right & Post-test & 10 & 21.01 & 4.62 & \\
\hline & Hand Gripping Force $(\mathrm{kg})$-left & Pre-test & 10 & 18.59 & 4.54 & \multirow[t]{2}{*}{.847} \\
\hline & Hand Gripping Force $(\mathrm{kg})$-left & Post-test & 10 & 18.41 & 4.79 & \\
\hline & “T” Test & Pre-test & 10 & 13.92 & 0.847 & \multirow[t]{2}{*}{.561} \\
\hline & “T” Test & Post-test & 10 & 13.86 & 0.898 & \\
\hline
\end{tabular}


Table 5. Comparison of pre-test and post-test values of the 8-week functional tennis training in the experimental group

\begin{tabular}{|c|c|c|c|c|c|c|}
\hline Group & Variables & Test & $\mathrm{N}$ & $\overline{\mathrm{x}}$ & sS & $P$ \\
\hline \multirow{12}{*}{ Experimental } & 10-m. Speed Run (s) & Pre-test & 10 & 2.25 & 0.21 & \multirow[t]{2}{*}{.007} \\
\hline & 10-m Speed Run (s) & Post-test & 10 & 2.10 & 0.20 & \\
\hline & Vertical Leap (kg.m/sn) & Pre-test & 10 & 22.70 & 6.14 & \multirow[t]{2}{*}{.004} \\
\hline & Vertical Leap (kg.m/sn) & Post-test & 10 & 25.90 & 6.17 & \\
\hline & Flexibility (cm) & Pre-test & 10 & 8.30 & 7.68 & \multirow[t]{2}{*}{.005} \\
\hline & Flexibility (cm) & Post-test & 10 & 12.70 & 8.22 & \\
\hline & Hand Gripping Force (kg)-right & Pre-test & 10 & 23.85 & 3.76 & \multirow[t]{2}{*}{.000} \\
\hline & Hand Gripping Force (kg)-right & Post-test & 10 & 27.45 & 4.38 & \\
\hline & Hand Gripping Force $(\mathrm{kg})$-left & Pre-test & 10 & 21.43 & 4.74 & \multirow[t]{2}{*}{.000} \\
\hline & Hand Gripping Force $(\mathrm{kg})$-left & Post-test & 10 & 24.86 & 4.76 & \\
\hline & "T" Test & Pre-test & 10 & 13.44 & 0.433 & \multirow[t]{2}{*}{.000} \\
\hline & "T" Test & Post-test & 10 & 12.35 & 0.479 & \\
\hline
\end{tabular}

It was determined that there was no significant difference between the control group of tennis players who applied 8-week routine tennis training, when the pre-test and post-test values related to the Wingate anaerobic power test were compared $(p>.05)$. A significant difference was found when the pre-test and post-test values related to the Wingate anaerobic power test of the experimental group tennis players who underwent 8-week functional tennis training were compared $(\mathrm{p}<0.01)$ (Table 6).

Table 6. Comparison of pre-test-post-test measurements of the group applying 8-week routine and functional tennis training program in terms of anaerobic capacity

\begin{tabular}{ccccccc} 
& & & & & & \\
& & Test & $N$ & $\bar{x}$ & sS & P \\
\hline \multirow{2}{*}{ WAnt } & \multirow{2}{*}{ Control } & Pre-test & 10 & 166.73 & 46.72 & .231 \\
& & & 10 & 161.44 & 55.75 & \\
\hline \multirow{2}{*}{ WAnt } & \multirow{2}{*}{ Experimental } & Pre-test & 10 & 172.11 & 51.22 & \multirow{2}{*}{022} \\
& & & 10 & 275.16 & 73.92 & \\
\hline
\end{tabular}

WAnt: Wingate Anaerobic Power Test

When the biomotor skills of the experimental and the control group of tennis players with 8-week functional and traditional routine tennis training and Wingate anaerobic power test measurements were compared, a significant difference was found in all variables in favour of the experimental group $(\mathrm{p}<0.01)$ (Table 7). When comparing the pre-test-posttest values in terms of inter-group anaerobic capacity of the group, which applied the 8 -week routine tennis and functional training program, a significant difference was found in favour of the experimental group ( $\mathrm{p}<0.01$ ) (Fig. 2). 
Table. 7. Comparison of intergroup pre-test and post-test values of the 8-week routine and functional tennis training in the experimental and control groups

\begin{tabular}{|c|c|c|c|c|c|c|c|}
\hline Variables & Group & $\mathrm{N}$ & Pre-test & Post-test & $\mathrm{sd}$ & $\mathrm{F}$ & Sig. \\
\hline \multirow{2}{*}{ 10-m Speed Run (s) } & Experimental & 10 & $2.25 \pm 0.21$ & $2.10 \pm 0.20$ & \multirow{2}{*}{18} & \multirow{2}{*}{14.260} & \multirow{2}{*}{.001} \\
\hline & Control & 10 & $2.46 \pm 0.24$ & $2.49 \pm 0.23$ & & & \\
\hline \multirow{2}{*}{ Vertical Leap (cm) } & Experimental & 10 & $22.70 \pm 6.14$ & $25.90 \pm 6.17$ & \multirow{2}{*}{18} & \multirow{2}{*}{10.929} & \multirow{2}{*}{.004} \\
\hline & Control & 10 & $18.70 \pm 8.01$ & $18.50 \pm 7.99$ & & & \\
\hline \multirow{2}{*}{ Flexibility (cm) } & Experimental & 10 & $6.20 \pm 10.74$ & $11.90 \pm 9.45$ & \multirow{2}{*}{18} & \multirow{2}{*}{21.834} & \multirow{2}{*}{.000} \\
\hline & Control & 10 & $6.50 \pm 5.38$ & $6.80 \pm 5.22$ & & & \\
\hline \multirow{2}{*}{$\begin{array}{l}\text { Hand Gripping Force } \\
\text { (kg)-right }\end{array}$} & Experimental & 10 & $23.85 \pm 3.76$ & $27.45 \pm 4.38$ & \multirow{2}{*}{18} & \multirow{2}{*}{57.686} & \multirow{2}{*}{.000} \\
\hline & Control & 10 & $20.94 \pm 4.18$ & $21.01 \pm 4.62$ & & & \\
\hline \multirow{2}{*}{$\begin{array}{l}\text { Hand Gripping Force } \\
\text { (kg)-left }\end{array}$} & Experimental & 10 & $21.43 \pm 4.74$ & $24.86 \pm 4.76$ & \multirow{2}{*}{18} & \multirow{2}{*}{62.799} & \multirow{2}{*}{.000} \\
\hline & Control & 10 & $18.59 \pm 4.54$ & $18.41 \pm 4.79$ & & & \\
\hline \multirow{2}{*}{ “T” Test (s) } & Experimental & 10 & $13.44 \pm 0.43$ & $12.35 \pm 0.47$ & \multirow{2}{*}{18} & \multirow{2}{*}{25.023} & \multirow{2}{*}{.000} \\
\hline & Control & 10 & $13.92 \pm 0.84$ & $13.86 \pm 0.89$ & & & \\
\hline
\end{tabular}

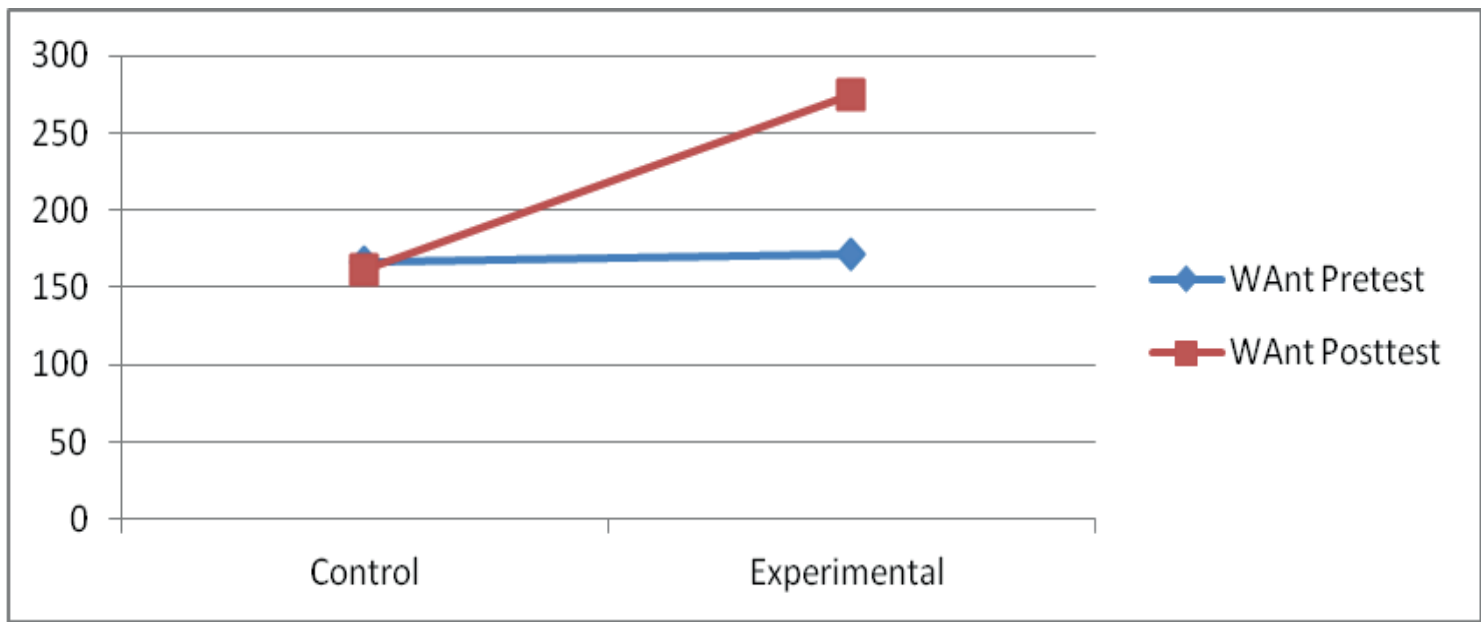

WAnT: Wingate Anaerobic Power Test

Fig. 2. Comparison of the pre-test-post-test measurements in terms of intergroup anaerobic capacity of the group for which the 8-week routine tennis and functional training program was applied

\section{DISCUSSION}

Scientific studies $[4,5,21]$ shows that functional training practices affect various physiological and biomotor features. Our study shows that there are statistically significant differences between the control and experimental group of girl tennis players before and after the test. It has been suggested that functional training can be as effective as traditional resistance training to increase muscle strength and endurance. According to the findings of the research, because there was no significant difference between anthropometric and demographic parameters, such as age, height, body weight and body fat percentage, it can be asserted that the differences in parameters related to biomotor skills (10m speed run, Vertical Jump, Flexibility, Hand Grip Force, T Test) and Wingate measurements between groups are not due to anthropometric and demographic features. In addition, the findings reveal that functional movement exercises related to tennis improve the biomotor skills of 10-12 year-old tennis players, when applied in parallel with routine tennis training. The literature review reveals few academic studies on functional training in children and child tennis players, and the effect of functional training when it is added to the training programs in addition to tennis training has not been examined [22, 23]. At the same time, 
there are some studies on the development of biomotor characteristics in children and the relationship between them are revealed. However, it is possible to argue that there is a limited number of studies on "functional training" with regard to the development of athletic performance and biomotor skills in children.

This study found that there was no significant difference regarding biomotor skills between the pre-test and post-test values of the control group of tennis players, who had routine tennis training. The reason for this is the fact that one-way practices are insufficient to develop biomotor skills. In our study, it was found that, when the pre-test and post-test values related to the biomotor skills of the experimental group of tennis players who were applied 8-week functional tennis training were compared, there was a significant difference in all variables. In our study, when comparing the pre-test and post-test values of the control group of tennis players who underwent 8-week routine tennis training, there was no significant difference regarding the Wingate anaerobic power test. In terms of anaerobic power, it can be said that routine tennis training alone is not effective in improving this feature. However, when the pre-test and post-test values of the experimental group of tennis players with 8-week functional tennis training were compared, there was a significant difference regarding the Wingate anaerobic power test. In the study by Song et al. [24], elite high school baseball players implemented a 16-week functional training program, and an increase in strength and flexibility was reported. In another study, Weiss et al. [25] investigated the effects of training methods on muscle strength and endurance, flexibility, agility, balance and anthropometric measurements by applying a 7-week functional training and traditional training program to 38 mixed gender participants between the ages of 18 and 32. In this study, a significant increase in the flexibility characteristics of only the functional training group was detected; contrary to the current study, no significant difference was found in other features. The results of this study support the results demonstrating that functional training has positive effects on biomotor properties.

In the functional training method, it was demonstrated that not only strength and endurance, but also flexibility, balance, coordination and deep sense improved by performing exercises by activating multiple muscles and joints in multiple planes and axes [16, 26-30]. However, the traditional method of training includes exercises to increase the strength and endurance of a particular muscle. These exercises are done in one way. Therefore, recovery with heavy loading is only fast in the corresponding muscle. In addition, routine / traditional training is designed to exercise with free weights in a supported or fixed position, or with stationary training tools. Therefore, it can be considered that the traditional training method alone cannot be sufficient to achieve the desired level of performance [31, 32-33]. As a reason, it is thought that one-way studies are insufficient to improve biomotor skills.

According to the findings, when the biomotor skills and Wingate anaerobic power test measurements of the 8-week functional and traditional routine tennis training practitioners and control group of tennis players were compared, there was a significant difference in all variables in favour of the experimental group. It can be argued that the reason for this significant difference is the functional training practices. In a study by Ylddz et al. [31], it is seen that the functional tennis training model is more effective than traditional tennis training model in terms of athletic performance improvement. When functional training (FT) is considered as a new training method for athletes, it is asserted that athletes develop features such as strength, flexibility, balance and coordination in the target movement in a more balanced way compared to traditional training, because in the functional training approach, movement training, not muscle training, is important. Shaikh and Mondal [34] examined in their study the effect of physical fitness parameters on high school students in 3 days a week for 8 weeks. In the study, it is suggested that functional training provides more muscle dominance, balance, more strength increase, changes in power distribution to large and small muscle groups, and more efficiency in a shorter time. In the study by Ju-sik [35], the effect of the functional exercise program 
on eight elite Taekwondo players for 6 weeks (three times a week, 60 minutes/session) was investigated. The Wingate test, which tested anaerobic capacity before and after application of training, showed that there was a statistically significant difference in all measurement items. Regarding anaerobic exercise ability, there was a significant increase in both peak power, average power, total power and peak power drop.

So, basic mobility skills are the basic skills that need to be improved by the age of 10 , and these skills are almost essential for any sport. Some biomotor skills of children should not be neglected while developing these basic movement skills. Therefore, when the age of specialization comes, children will be able to realize easily their special mobility skills.

\section{CONCLUSION}

Functional training practices were performed to demonstrate its contribution to developing biomotor skills when applied in conjunction with routine tennis training, which we consider to be one-way. The findings reveal that functional training performed by imitating tennis, parallel to routine tennis training, improves the biomotor skills of 10-12 year-old tennis player girls. According to the research results, with Wingate (Anaerobic Power) test, regarding the biomotor skills of the control and the experimental group of tennis players who performed the 8-week routine and functional tennis training (10-m speed run, vertical leap, flexibility, Hand Gripping Force (kg)-right and Hand Gripping Force (kg)-left, "T" Test), comparing pre-test and post-test values within and between the groups, there was a significant increase in the experimental group that applied functional tennis training. In this case, it can be suggested that, depending on the design of FT exercises for young tennis players for at least 8 weeks, it contributes significantly to the development of anaerobic capacity as well as biomotor skills. Although working muscles develop individual motor skills, the quality of movement may decrease if the exercises are not performed in accordance with the principles of functional movement (exercises are often performed in one joint and on one plane). Muscles that do not communicate and cooperate with each other as a result of single-joint and single-plane exercises will cause problems in movements. For this reason, it may be recommended that athletes and trainers execute trainings according to the FT principles.

\section{REFERENCES}

[1] Turna B, Alp M. The effects of functional training on some biomotor abilities and physiological characteristics in elite soccer players. J Education Learn. 2020;9(1):164-171. https://doi.org/10.5539/jel.v9n1p164

[2] Crawford D, Drake N, Carper M, DeBlauw J, Heinrich K. Are changes in physical work capacity induced by highintensity functional training related to changes in associated physiologic measures? Sports. 2018;6(2):26. https:// doi.org/10.3390/sports6020026

[3] Tibana R, de Sousa N, Cunha G, et al. Validity of session rating perceived exertion method for quantifying internal training load during high-intensity functional training. Sports. 2018;6(3):68. https://doi.org/10.3390/sports6030068

[4] Claudino JG, Gabbett TJ, Bourgeois F, et al. Crossfit overview: systematic review and meta-analysis. Sports Medicine - Open. 2018;4(1):11. https://doi.org/10.1186/s40798-018-0124-5

[5] De Sousa AF, dos Santos GB, dos Reis T, et al. Differences in physical fitness between recreational crossfit ${ }^{\circledR}$ and resistance trained individuals. J Exerc Physiol Online. 2016;19(5).

[6] Feito Y, Heinrich K, Butcher S, Poston W. High-intensity functional training (HIFT): Definition and research implications for improved fitness. Sports. 2018;6(3):76. https://doi.org/10.3390/sports6030076

[7] Maté-Muñoz JL, Lougedo JH, Barba M, García-Fernández P, Garnacho-Castaño MV, Domínguez R. (2017). Muscular fatigue in response to different modalities of crossfit sessions. PloS One. 2017;12(7):e0181855. https://doi.org/10.1371/ journal.pone.0181855

[8] Soslu R, Özer Ö, Güler M, Doğan AA. Is there any effect of core exercises on anaerobic capacity in female basketball players? J Educ Training Stud. 2019;7(3):99-105. https://doi.org/10.11114/jets.v7i3.3959

[9] Heinrich KM, Spencer V, Fehl N, Carlos Poston WS. Mission essential fitness: comparison of functional circuit training to traditional army physical training for active duty military. Military Med. 2012;177(10):1125-1130. https://doi. org/10.7205/MILMED-D-12-00143

[10] Barfield JP, Channell B, Pugh C, Tuck M, Pendel D. Format of basic instruction program resistance training classes: Effect on fitness change in college students. Phys Educator. 2012;69(4):325. 
[11] Delgado-García G, Vanrenterghem J, Muñoz-García A, Ruiz-Malagón EJ, Mañas-Bastidas A, Soto-Hermoso VM. Probabilistic structure of errors in forehand and backhand groundstrokes of advanced tennis players, Int J Perform Analysis Sport. 2019;19(5):698-710. https://doi.org/10.1080/24748668.2019.1647733

[12] Çiftçi T. Effect of 12-week basic tennis training on tennis skills, strength and simple reaction time of children. Unpublished master thesis. Gazi University Health Sciences Institute; 2017.

[13] Bompa TO. Training theory and management 2. Baskı, Ankara: Bağırgan Publisher, 2001, $459-475$.

[14] Kovacs MS. Applied physiology of tennis performance. Br J Sport Med. 2006;40(5):381-5. https://doi.org/10.1136/ bjsm.2005.023309

[15] Fahlman MM, McNevin N, Boardley D, Morgan A, Topp R. Effects of resistance training on functional ability in elderly individuals. Am J Health Promotion. 2011;25(4):237-243. https://doi.org/10.4278/ajhp.081125-QUAN-292

[16] Boyle M. Functional Trainıng for Sports. Champaign, Il.: Human Kinetics; 2004.

[17] Hashidate H, Shiomi T, Sasamoto N. Effects of 3-month combined functional training at an adult day-care facility on lower extremity muscle strength and gait performance in community-dwelling people with chronic hemiplegia. J Phys Ther Sci. 2011;23(4):607-611. https://doi.org/10.1589/jpts.23.607

[18] Kilbride CB, Norris M, Mohagheghi AA. Exploring the feasibility, acceptability and efficacy of a community-based functional training programme (ARNI) for stroke survivors: A pragmatic mixed-methods study. Int J Stroke. 2012;7:76-76.

[19] Hopkins WG. Measures of reliability in sports medicine and science. Sports Med. 2000;30(1):1-15. https://doi. org/10.2165/00007256-200030010-00001

[20] Alpar R. Multivariate statistical methods. Türkiye, Ankara: Detay Publisher; 2013.

[21] Hermassi S, Wollny R, Schwesig R, Shephard RJ, Chelly MS. Effects of in-season circuit training on physical abilities in male handball players. J Strength Condition Res. 2017;33(4):944-957. https://doi.org/10.1519/JSC.0000000000002270

[22] Brokaw EB, Murray TM, Nef T, Lum PS, Brokaw EB, Nichols D, Lum PS. Time Independent functional task training: A case study on the effect of inter joint coordination driven haptic guidance in stroke therapy. 2011 IEEE International Conference on Rehabilitation Robotics (Icorr); 2011. https://doi.org/10.1109/ICORR.2011.5975501

[23] Cai ZG, Shi XJ, Lu XG, Yang ZH, Yu GY. Efficacy of functional training of the facial muscles for treatment of incomplete peripheral facial nerve injury. [Randomized Controlled Trial Research Support, Non-U.S. Gov't]. Chin J Dental Res. 2010;13(1):37-43.

[24] Song HS, Woo SS, So WY, Kim KJ, Lee J, Kim JY. Effects of 16-week functional movement screen training program on strength and flexibility of elite high school baseball players. J Exerc Rehabil. 2014;10:124-130. https://doi. org/10.12965/jer.140101

[25] Weiss T, Kreitinger J, Wilde $\mathrm{H}$, et al. Effect of functional resistance training on muscular fitness outcomes in young adults. J Exerc Sci Fitness. 2010;8:113-122. https://doi.org/10.1016/S1728-869X(10)60017-2

[26] Blasco-Lafarga C, Martinez-Navarro I, Pablos C. Six weeks of functional training enhances balance, strength and cardiovascular endurance among postmenopausal women. J Aging Phys Activ. 2012;20:S254-S255.

[27] Cook G, Burton L, Kiesel K, Rose G, Bryant MF. Movement: Functional movement systems - screening, assessment, corrective strategies. USA: On Target Publications; 2010.

[28] Yıldız S. Relationship between functional movement screen and some athletic abilities in karate athletes. J Educ Train Stud. 2018;6:66-69. https://doi.org/10.11114/jets.v6i8.3352

[29] Lohne-Seiler H, Torstveit MK, Anderssen SA. Traditional- versus functional strength training. effects on muscular strength and power among elderly. J Aging Phys Activ. 2012 Jan;21(1):51-70. https://doi.org/10.1123/japa.21.1.51

[30] Whitehurst MA, Johnson BL, Parker CM, Brown LE, Ford AM. The benefits of a functional exercise circuit for older adults. [Research Support, Non-U.S. Gov't]. J Strength Condition Res. 2005;19(3):647-651. https://doi. org/10.1519/R-14964.1

[31] Yıldız S, Pınar S ve Gelen E. Effects of 8-week functional vs. traditional training on athletic performance and functional movement on prepubertal tennis players. J Strength Condition Res. 2019;3(3):651-661. https://doi.org/10.1519/ JSC.0000000000002956

[32] Gudlaugsson J, Gudnason V, Aspelund T, et al. Effects of a 6-month multimodal training intervention on retention of functional fitness in older adults: A randomized-controlled cross-over design. Int J Behav Nutr Phys Activ. 2012;20:S89. https://doi.org/10.1186/1479-5868-9-107

[33] Hashidate H, Shiomi T, Sasamoto N. Effects of 6 months combined functional training on muscle strength, postural balance and gait performance in community-dwelling individuals with chronic stroke hemiplegia. J Phys Ther Sci. 2011;23(4):617-623. https://doi.org/10.1589/jpts.23.617

[34] Shaikh A, Mondal S. Effects of functional training on physical fitness components on college male students A pilot study. J Humanities Soc Sci. 2012;1(2):1-5. https://doi.org/10.9790/0837-0120105

[35] Ju-sik P. The effect of functional training on the physical strength factor of elite taekwondo athletes. Kinesiology. 2019;4(1):1-7. https://doi.org/10.22471/sport.2019.4.1.01 